\title{
A new species of Siamoglaris from Thailand with complementary description of the type species (Psocodea: 'Psocoptera': Prionoglarididae)
}

\author{
Charles LIENHARD \\ Muséum d'histoire naturelle, c. p. 6434, CH-1211 Genève 6, Switzerland. \\ E-mail: charleslienhard@bluewin.ch
}

\begin{abstract}
A new species of Siamoglaris from Thailand with complementary description of the type species (Psocodea: 'Psocoptera': Prionoglari didae). - A new species of the previously monotypic genus Siamoglaris Lienhard, S. theresiae sp. n., is described and illustrated, based on three males from Thailand (female unknown). The female of the type species, $S$. zebrina Lienhard, is described for the first time and complements to the description of the male of this species are given. The generic diagnosis is revised. For the first time in Psocoptera, numerous thin-walled papilliferous spatulate setae (scent setae?) were observed on female gonapophyses and paraprocts; they are illustrated by scanning electron micrographs. Figures of female terminalia of the closely related genus Prionoglaris Enderlein are also presented.
\end{abstract}

Keywords: Prionoglaridinae - Prionoglaris - scent setae - living fossils.

\section{INTRODUCTION}

The psocids mentioned in this study have been collected by the Thailand Inventory Group for Entomological Research (TIGER) in the course of their project on the insect fauna of Thailand, the field work of which was realized during the years 2006-2009 (see: http://sharkeylab.org/tiger/). The present paper contains the first published results on psocids collected during this monumental faunistic survey. 1839 samples containing psocids were sent to the Muséum d'histoire naturelle of the City of Geneva (Switzerland), where thousands of specimens were labeled and sorted to morphospecies by Mrs Thérèse Cuche. About 20 families of Psocoptera are represented in this material. One of them, the Prionoglarididae, is treated in the present paper; it is represented by 17 specimens of the endemic genus Siamoglaris Lienhard, 2004.

Within the order Psocodea (sensu Yoshizawa \& Johnson, 2006) the 'Psocoptera' family Prionoglarididae belongs to the basal suborder Trogiomorpha and has recently been placed in an infraorder of its own, the Prionoglaridetae (see Yoshizawa et al., 2006). Due to their basal position within Trogiomorpha and their similarity to fossils of this suborder, based on a plesiomorphic wing venation, the extant prionoglaridids are considered as "living fossils" (Lienhard, 2007). The family has been subdivided into two subfamilies by Lienhard (2004), Prionoglaridinae and Speleketorinae. The nominate subfamily contains the Palaearctic genus Prionoglaris Enderlein (3 species; see Lienhard \& Smithers, 2002), the Neotropical genus Speleopsocus Lienhard (mono- 
typic; see Lienhard et al., 2010a) and the previously monotypic Oriental genus Siamoglaris Lienhard (Lienhard, 2004).

The latter genus was represented in the TIGER-project material by 9 males and 5 females belonging to the type species, Siamoglaris zebrina Lienhard, 2004, previously only known from the male holotype. The female is described in the following and complements to the description of the male are given. The remaining three Siamoglaris individuals discovered in this material are males and represent a new species described below. Based on these data a revised generic diagnosis is proposed and some morphological characters are discussed.

\section{MATERIAL AND METHODS}

Dissection and slide-mounting followed the methods described by Lienhard (1998). After clearing the male terminalia in lactophenol, complete or partial eversion of the retracted eversible distal structures of the phallosome could be provoked by a short immersion (some minutes) in Sellnick fluid (Sellnick, 1960: 45; Weidner, 1993: 5; Lienhard, 1998: 60), while observing the phallosome under a stereomicroscope.

The material examined is deposited in the arthropod collections of the Muséum d'histoire naturelle, Geneva, Switzerland (MHNG) and of the Queen Sirikit Botanical Gardens, Mae Rim, Chiang Mai Province, Thailand (QSBG). For all material examined the TIGER-project sample numbers are mentioned (T-number).

The following abbreviations are used in the descriptions: $\mathrm{BL}=$ body length (in alcohol); F = hindfemur (length); FW = forewing (length); HT = holotype; HW = hindwing (length); IO/D = shortest distance between compound eyes divided by anteroposterior diameter of compound eye in dorsal view of head; $\mathrm{PT}=$ paratype; $\mathrm{T}=$ hindtibia (length); t1, t2, t $3=$ tarsomeres of hindtarsus (length, measured from condyle to condyle).

\section{DESCRIPTIONS AND DISCUSSIONS}

Siamoglaris Lienhard, 2004

Lienhard, 2004: 866. Type species: Siamoglaris zebrina Lienhard, 2004: 866. Other species included: Siamoglaris theresiae sp. n. (see description below).

REVISED DIAGNOSIS: See original diagnosis by Lienhard (2004), with the following additions or modifications. Habitus as shown in Fig. 1. Membranous extension of anterior preapical claw of each leg somewhat variable in size (Fig. 5e and Lienhard, 2004: fig. 5; see also Discussion below). Male terminalia (Figs 4a-c, 5f-g, 6c-e): Mediointernal structure of posterior part of phallosome not differentiated as a simple slender process like in Prionoglaris (see Lienhard, 1988, 1998), but as a relatively wide and weakly sclerotized internal tube bearing distally the opening of the ejaculatory duct and various membranous or sclerotized eversible structures of specific shapes. Female terminalia (Figs 2-3): In general similar to Prionoglaris (Fig. 7), but ovipositor valvulae and paraprocts lacking hooked stout setae and basal part of epiproct lacking pilosity. Ventral and dorsal gonapophyses almost completely reduced. External gonapophyses well-developed, basally rounded, apically angulate, pilose; besides normal pilosity bearing also numerous thin-walled broadened papilliferous setae (Figs 2b, 3). Some such setae also present in ventral half of paraproct (Fig. 3a). 
Subgenital plate short and simple, its posterior margin forming a wide angle but lacking a distinct medio-apical lobe. Spermapore region simple.

Discussion: The shape of the membranous part of the anterior preapical claws is somewhat variable (partially due to different degrees of swelling after slidemounting of the legs). Contrary to Lienhard (2004: key on p. 871) no clear difference between Siamoglaris and Prionoglaris could be observed in this character (see Figs 5e and $7 \mathrm{~b}$ ). The internal basal bristle of the anterior pretarsal claws is also present in Prionoglaris (Fig. 7b), but usually it is very short and fine, difficult to distinguish from adjacent microtrichia; therefore it has not previously been recognized by Lienhard (1988: fig. 8; 1998: fig. 39e). The other differences between these two genera mentioned by Lienhard (2004) could be confirmed. However, in Prionoglaris the posterior parts of the phallosome are more heavily sclerotized than in Siamoglaris and no eversible structures have been observed. The opening of the ejaculatory duct is hardly visible in Prionoglaris, probably it is situated just dorsally of the base of the medioventral process near the base of the mediointernal process (see figures in Lienhard, 1988, 1998). Lienhard (2004) has tentatively interpreted the presence of a pair of sclerotized hooked claspers apically on the eversible posterior parts of the phallosome as a generic character of Siamoglaris, but the new material shows that this character is only present in the type species.

The female genitalia of Siamoglaris are similar to those of the other priono glaridine genera (Prionoglaris: Fig. 7e; Speleopsocus: see Lienhard et al., 2010a: fig. $3 b)$. The presence of special papilliferous setae on female terminalia of S. zebrina is here tentatively interpreted as an autapomorphy of the genus Siamoglaris (see also Discussion of the type species, below). The female of the monotypic Neotropical genus Speleopsocus, the male of which is still unknown, can easily be distinguished from Siamoglaris by several striking characters, as indicated by Lienhard et al. (2010a). The discovery of the female of Siamoglaris does not provide significant new information for a better understanding of phylogenetic relationships between the three genera of Prionoglaridinae. The trichotomy in this subfamily remains unresolved (see Lienhard et al., 2010a). At present it seems that only molecular data (DNA analysis will be undertaken by Kazunori Yoshizawa, Sapporo) or the discovery of the male of Speleopsocus can bring some progress in this field.

Siamoglaris zebrina Lienhard, 2004

Figs 1-4

Siamoglaris zebrina Lienhard, 2004: 866; description of male.

TyPE MATERIAL: MHNG, ơ holotype (re-examined), Thailand, Kanchanaburi Province, Sai Yok District, near Wang Badan Cave, ca. $2 \mathrm{~km} \mathrm{~N}$ of Sai Yok Noi Waterfall, dry stream bed (on low vegetation), 9.xii.2003, leg. P. Schwendinger.

New MATERIAL EXAMINED: MHNG and QSBG, Thailand, Kanchanaburi Province, Khuean Srinagarindra National Park, $9 \delta^{\star}$ and $5 q$ in Malaise traps from the following localities, leg. TIGER-project: Huai Mae Kamint / Tourist center (1ठ, 11-18.ix.2008, T3442; $2 \delta, 2 \uparrow$,

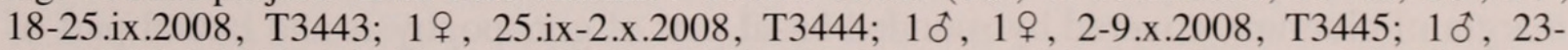
30.x.2008, T3463; 1 \%, 30.x-6.xi.2008, T3464); Tha Thung-na / Chong Kraborg (1 0 , 1 ㅇ , 30.x6.xi.2008, T3472; 20 , lacking abdomen, 6-13.xi.2008, T4431, these two specimens could be identified as males due to their small body size and their relatively large compound eyes, i.e. IO/D 1.16 and 1.15, see also Complementary description of male, below). 


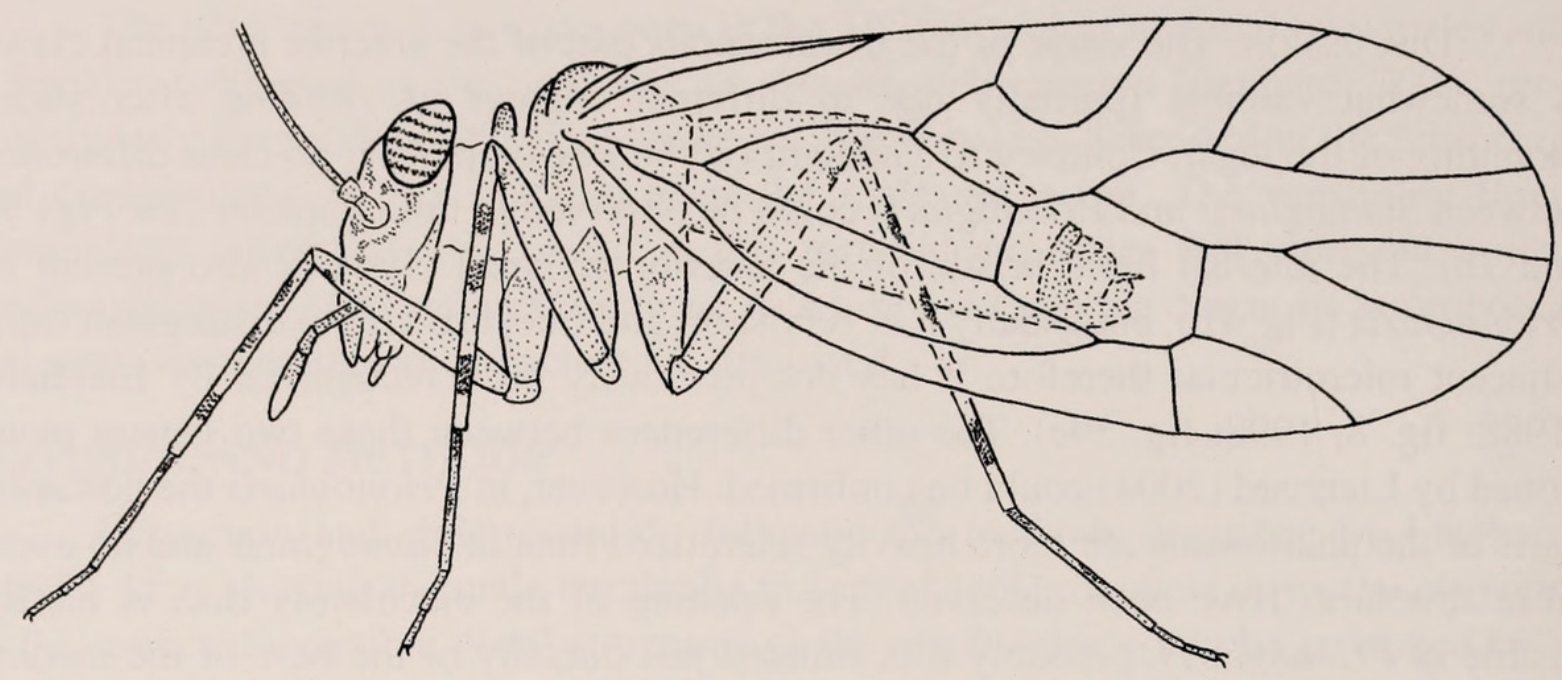

FIG. 1

Siamoglaris zebrina Lienhard, male: Habitus, lateral view (body length $2.5 \mathrm{~mm}$ ); antenna incomplete; pilosity, hindwing and right appendages not shown.

DESCRIPTION OF FEMALE: Colouration and general morphology as described for male by Lienhard (2004). Body size distinctly larger than in male, but compound eyes relatively smaller (see Complementary description of male, below). Femora lacking dark brown transversal band of hypodermal pigment in 2/3 of their length (Fig. 4d, cf. Fig. 5i showing this band in $S$. theresiae). Colour pattern of eyes not well-preserved in the specimens examined (observed after two years in alcohol), but still partially visible (cf. Fig. 5a). Pterostigma colourless, transparent or very slightly opaque. Antennae damaged in all specimens examined. Anterodorsal region of abdomen without small humps (see also Fig. 6f, showing pair of humps present in male of $S$. theresiae). Terminalia shown in Figs 2, 3; see also revised generic diagnosis, above. Epiproct relatively small, pilosity only developed in apical half, consisting of a pair of long setae and some shorter hairs. Paraproct in middle with a transversal row of some long setae, in its apical half with a dense group of hairs, some of them differentiated as papilli ferous setae, similar to those on the external gonapophysis (in some cases weakly differentiated, see Fig. 2b: 4); sense cushion well-differentiated, bearing one normal seta and numerous fine trichobothria, the latter without basal rosettes. Subgenital plate short, with a anteriorly narrowing pigmented area. External gonapophyses welldeveloped, bearing some long stout setae and many shorter acuminate hairs; towards posteroventral margin with numerous apically thin-walled and usually slightly curved papilliferous spatulate or club-shaped setae of unknown function (see Discussion, below). An approximately oval structure present on each side at base of external gonapophysis (shown by interrupted lines in Fig. 2a), originating from anteroventral margin of clunium, covered by rounded basal part of gonapophysis and lateral part of subgenital plate (rudiments of ventral and dorsal gonapophyses?). Spermapore region with a weakly sclerotized suboval posterior area and a membranous anterior area bearing the spermapore. Spermathecal duct very long and more or less spirally coiled 


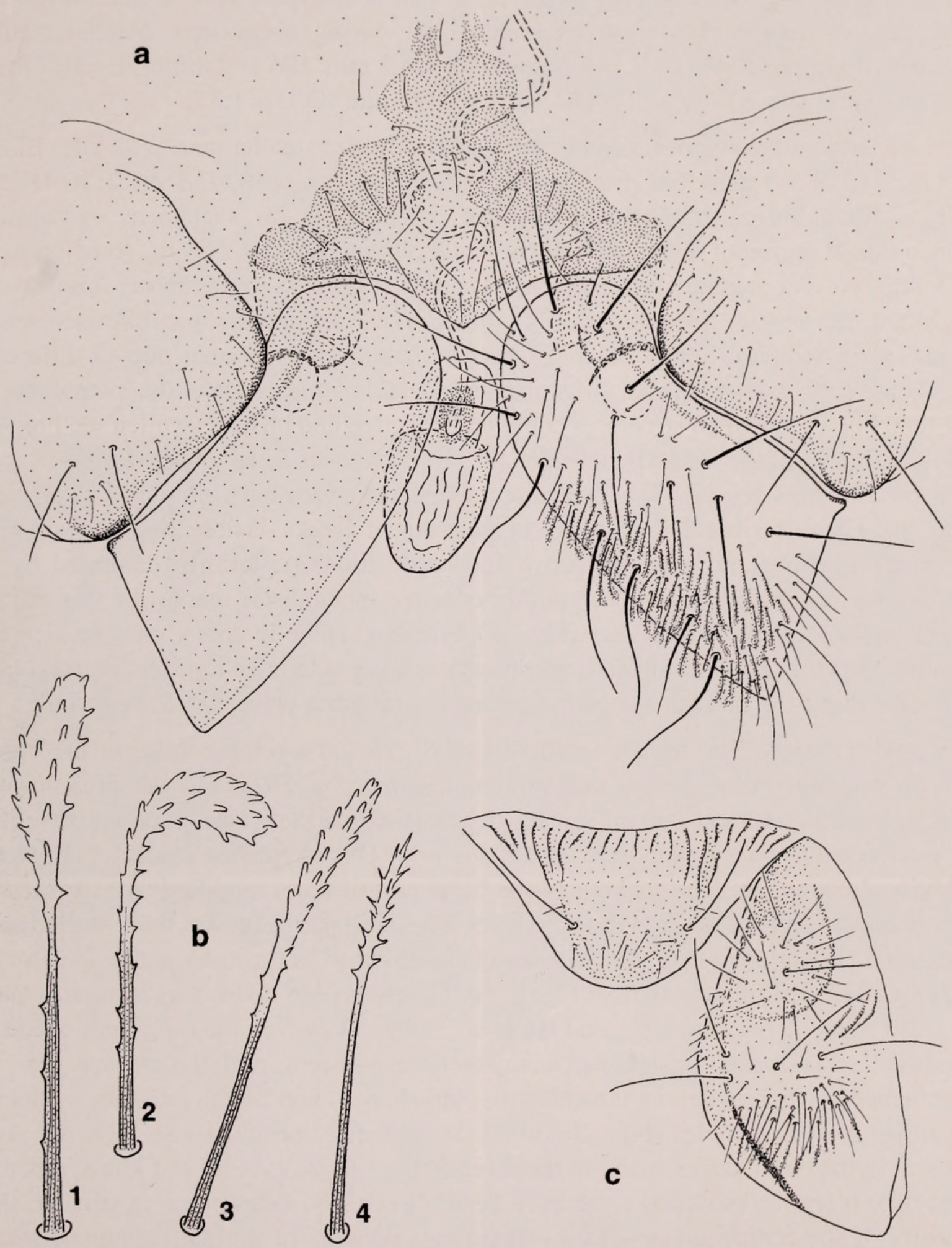

FIG. 2

Siamoglaris zebrina Lienhard, female: (a) Subgenital plate, ovipositor valvulae (pilosity on right side not figured), ventrolateral parts of clunium, spermapore region and distal part of spermathecal duct. (b) Papilliferous setae on external gonapophysis and paraproct; 1 erect seta, 2 curved seta, 3 slender seta, 4 weakly differentiated seta. (c) Epiproct and right paraproct. 
(at least more than twice as long as the distal part of the spermathecal duct shown in Fig. 2a), spermathecal sac not examined (lost during dissection). Measurements (female of sample T3472): $\mathrm{BL}=3.5 \mathrm{~mm} ; \mathrm{FW}=4.2 \mathrm{~mm} ; \mathrm{HW}=2.8 \mathrm{~mm} ; \mathrm{F}=917 \mu \mathrm{m}$; $\mathrm{T}=1610 \mu \mathrm{m} ; \mathrm{t} 1=818 \mu \mathrm{m} ; \mathrm{t} 2=182 \mu \mathrm{m} ; \mathrm{t} 3=185 \mu \mathrm{m} ; \mathrm{IO} / \mathrm{D}=1.35$.

COMPLEMENTARY DESCRIPTION OF MALE: Body size smaller than in female (BL $\delta$ $<3 \mathrm{~mm}$; $\mathrm{BL} q>3 \mathrm{~mm})$, but compound eyes relatively larger $\left(\mathrm{IO} / \mathrm{D}{ }^{\tau}<1.2\right.$; $\mathrm{IO} / \mathrm{D} q>$ 1.3). Colouration as in female. Antennae damaged in all specimens examined. Anterodorsal region of abdomen without small humps (see also Fig. 6f, showing pair of humps present in male of $S$. theresiae). Terminalia (Fig. 4a-c): Paraproct simple (see Lienhard, 2004: fig. 14), its pilosity normal (i.e. lacking the papilliferous setae observed in female). Shape of apical part of phallosome variable due to different positions of the eversible distal structures and variable tumescence of the membranous blisters. For a view of all structures completely everted and blisters swollen see Fig. $4 \mathrm{c}$ and the figures of the holotype in Lienhard (2004); for retracted apical structures and collapsed blisters see Fig. 4a; for everted apical structures but collapsed blisters see Fig. 4b. Characteristical distal pair of sclerotized hooks visible in all positions. Rounded medioventral process (sensu Lienhard, 2004) posteriorly delimited by a transversal reticulate membrane; slightly concave mediodistal margin of this membrane well visible in ventral view (Fig. 4b), but also visible in dorsal view on cleared phallosome (Fig. 4c, interrupted line), always lacking sclerotized posterolateral lobes (see also Figs 5f, g and 6d, e showing posterolateral lobes present in S. theresiae).

Discussion: The female terminalia of $S$. zebrina resemble those of the other known prionoglaridine genera due to symplesiomorphy. However, the presence of special papilliferous setae on the gonapophyses (some of them also on paraprocts) can be interpreted as an autapomorphy of Siamoglaris. This interesting character deserves additional comments. The socket and the basal part of these modified setae are identical to those of the adjacent acuminate hairs. The basal part is brown, thick-walled and longitudinally grooved (Fig. 2b) as usual in chaetal sensilla (grooves not visible in the scanning electron micrographs of Fig. 3, but clearly visible under a light microscope; see also Slifer \& Sekhon, 1977 and Hu et al., 2009). However, the distal half of these modified setae is thin-walled and completely transparent, and the surface area is augmented by its broadening (spatulate to club-shaped) and by the presence of many small papilliform spicules (Figs 2b; 3d, f). Several more acuminate spicules are also present in the basal half of many of these setae (Figs 2b, 3c). As far as I know, it is the first time that such modified setae have been observed in Psocoptera. In general, the pilosity of the female gonapophyses of psocids consists of normal acuminate setae (probably mechanoreceptors). The particular morphology of these modified setae suggests a possible function as scent organs involved in sexual behaviour (emitting an aphrodisiac pheromone?). Brush-like pheromone-diffusing scent scales of somewhat similar morphology have been observed in several Lepidoptera (Grassé, 1975; Wüest, 1996).

The presence of eversible distal structures on the phallosome, often retracted in alcohol preserved specimens, may pose a problem for the interpretation of the micromorphology of the posterior part of the phallosome. Therefore they have been illus- 

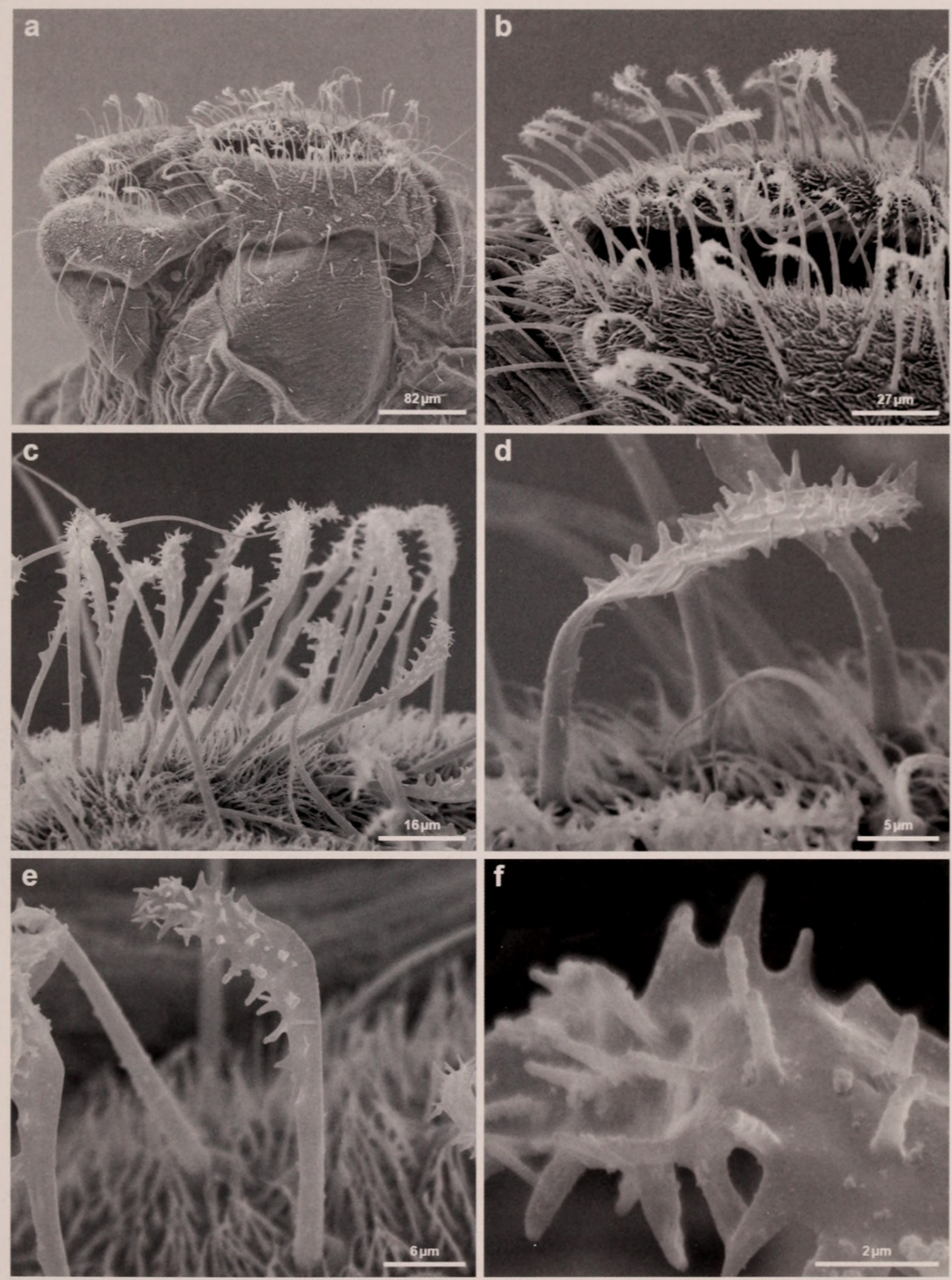

Fig. 3. Siamoglaris zebrina Lienhard, female, scanning electron micrographs (made by A. Piuz, MHNG): (a) Abdominal apex (ventral side above, paraprocts left). (b) Posteroventral margin of external gonapophyses (same position as in Fig. 3a). (c) Papilliferous setae on posteroventral margin of external gonapophysis. (d) Papilliferous seta on posteroventral margin of external gonapophysis (same seta also recognizable in Fig. 3b, slightly left above middle). (e) Ditto (other seta, not recognizable in Fig. 3b). (f) Detail of apical part of same seta. 


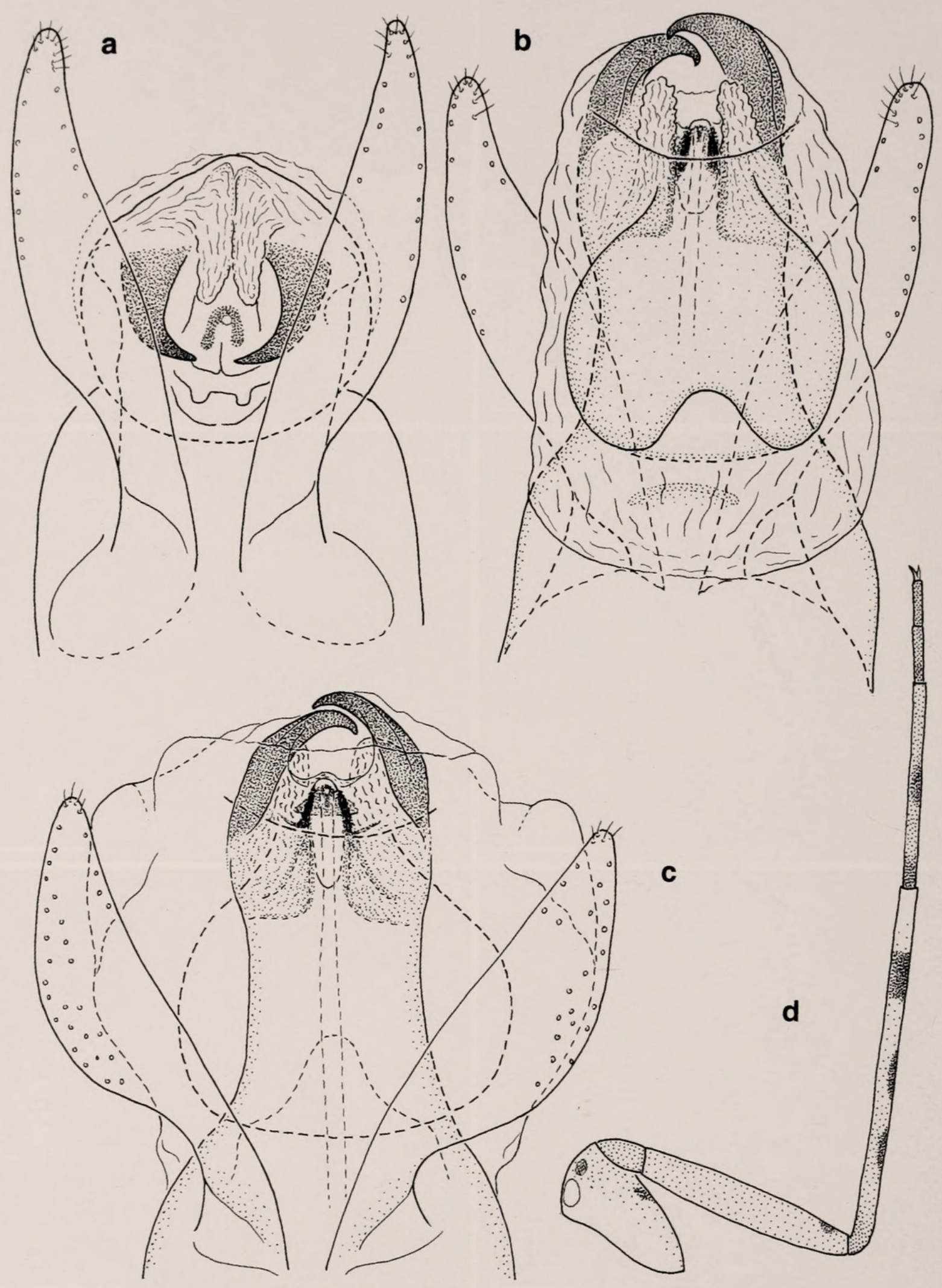

FIG. 4

Siamoglaris zebrina Lienhard, male: (a) Posterior part of phallosome (dorsal view) with retracted distal structures. (b) Ditto (same specimen, ventral view) after artificially provoked eversion of distal structures (see Material and methods). (c) Ditto (other specimen, dorsal view) with naturally everted distal structures and swollen membranous blisters. (d) Hindleg (pilosity not shown). 
trated here in the retracted (Fig. 4a) and in the everted position (Fig. 4b, c). In Fig. 4c the membranous blisters of this region of the phallosome are presented in the swollen position, though not exhibiting the maximal swelling as shown for the holotype by Lienhard (2004: fig. 11). In this figure of the holotype the slightly concave mediodistal margin of the reticulate membrane is not well recognizable (probably due to the excessive swelling of lateral blisters), but in the re-examined phallosome of the holotype it is well visible (blisters collapsed after permanent slide-mounting). The eversion of the distal structures of the phallosome could be directly observed under the stereo microscope for the specimen shown in Fig. 4a, b (see Material and methods). In the retracted position the distal part of the phallosome is anterodorsally folded and the tips of the pair of sclerotized claspers are anteriorly directed, well visible in dorsal view (Fig. 4a). During eversion this part rises dorsally and finally unfolds backwards, so that the free tips of the hooked claspers are situated at the posterior end of the phallosome (Fig. 4b). Several intermediate states can be observed in alcohol preserved material. When identifying males of Siamoglaris one has to pay attention to this phenomenon and not mistake it for variation in the morphology of the terminal structures of the phallosome. For a distinction between $S$. zebrina and $S$. theresiae see Discussion of the latter species.

Almost nothing is known about the biology of this species. The type locality is situated about 200-300 m from the main entrance of Wang Badan Cave, in a rocky limestone region full of subterranean crevices (Lienhard, 2004). The new material has been collected in a very similar limestone region of Kanchanaburi Province. Therefore it seems possible that Siamoglaris zebrina has some affinities to caves or similar subterranean habitats, at least during its nymphal life, as known for most Prionoglarididae (see Lienhard et al., 2010a, 2010b).

Siamoglaris theresiae $\mathrm{sp} . \mathrm{n}$.

Figs 5-6

HolotyPE: QSBG, ô (on 3 microscopical slides), Thailand, Chiang Mai Province, Doi Chiang Dao Wildlife Sanctuary, nature trail, 491m, Malaise trap, 30.ix-7.x.2007, leg. Songkran \& Apichart, T3174.

PARATYPES: MHNG, $2 \hat{0}$, Thailand, Kamphaeng Phet Province, Mae Wong National Park, Chong Yen, 1306m, Malaise trap, 8-15.x.2007, leg. C. Piluek \& A. Inpuang (T3686) and 17-24.iii.2008, leg. C. Piluek (T3641).

DESCRIPTION OF MALE (female unknown): Habitus as in S. zebrina (cf. Fig. 1). Colouration in general as describd for S. zebrina by Lienhard (2004), with the following slight differences: head anteroventrally with more dark pigment (Fig. 5a); colour pattern of the legs highly contrasted, femora with a dark brown transversal band of hypodermal pigment in $2 / 3$ of their length (Fig. 5i); some brown pigmentation present along the pterostigmal veins in forewing (Fig. 6a of PT, forewings of HT damaged). Colour pattern of eyes not well-preserved in the specimens examined (after 2-3 years in alcohol) but still partially visible (Fig. 5a). General morphology as described for S. zebrina by Lienhard (2004), with the following differences. Vertex with a pair of small lateral protuberances near compound eyes (Fig. 5a). Antennae damaged in all specimens examined. Both maxillary palps broken in HT. Maxillary palp of PT (sample T3641) as figured for S. zebrina by Lienhard (2004: figs 1 and 10), its terminal article with 5 thin-walled conical sensilla in apical half (as figured for 


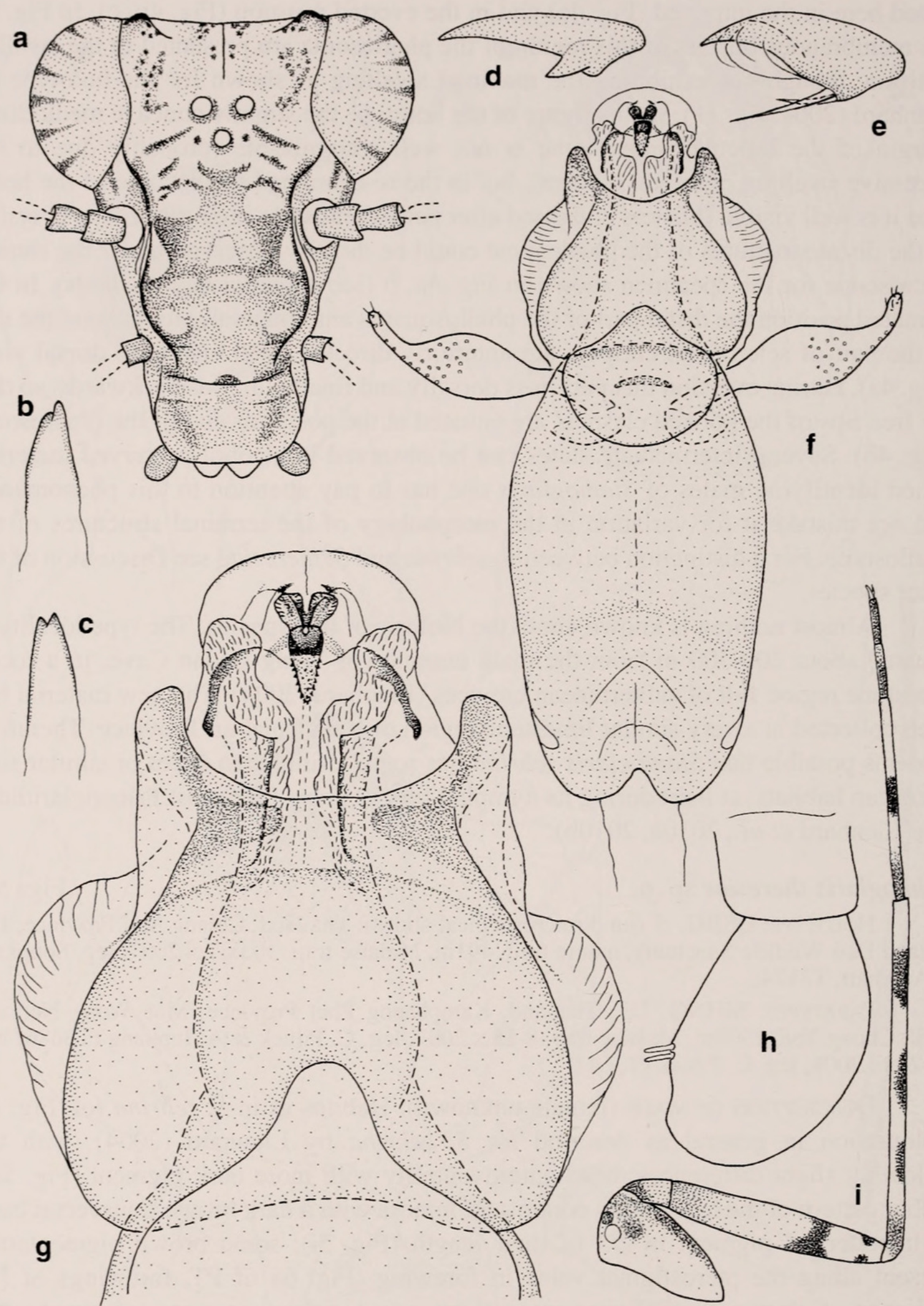

FIG. 5

Siamoglaris theresiae sp. n., male holotype: (a) Head (frontal view, pilosity not shown). (b) Remnant of left lacinia (length about $70 \mu \mathrm{m}$ ). (c) Remnant of right lacinia. (d) Posterior pretarsal claw of midleg (internal view). (e) Anterior pretarsal claw of midleg (external view). (f) Phallosome (ventral view) with naturally everted distal structures and slightly swollen blisters. (g) Posterior part of phallosome (ventral view) showing details of everted distal structures. (h) Labial palpus (pilosity not shown, except for thin-walled internal sensilla). (i) hindleg (pilosity not shown). 

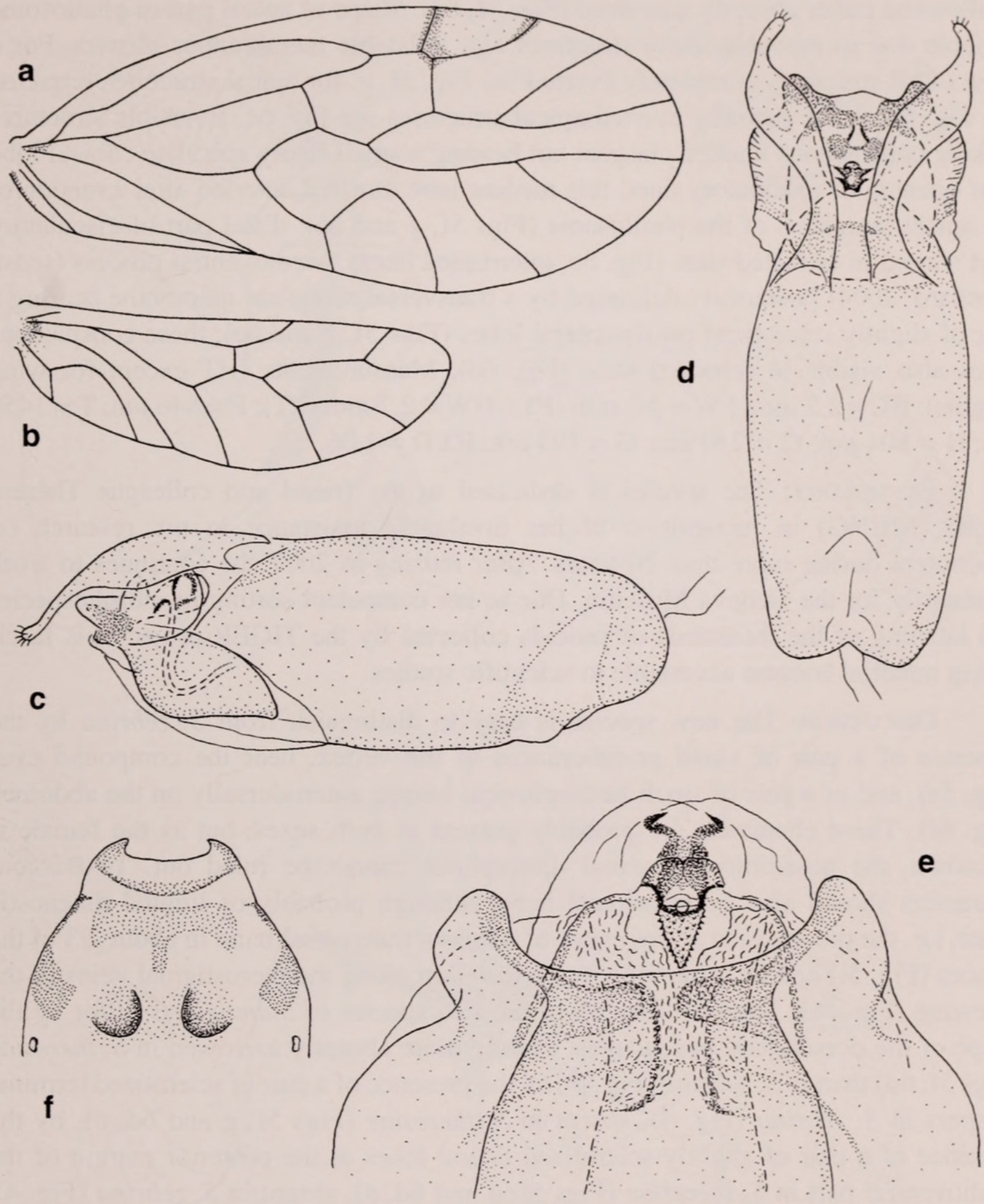

FIG. 6

Siamoglaris theresiae sp. n., male paratype (sample T3686): (a) Forewing. (b) Hindwing. (c) Phallosome (lateral view) with retracted distal structures. (d) Ditto (dorsal view). (e) Posterior part of phallosome (ventral view) with artificially provoked partial eversion of distal structures (see Material and methods). (f) Abdominal base (dorsal view) showing pair of small hemispherical humps anteromedially of spiracles of segment 3 .

S. zebrina by Lienhard, 2007: fig. 3b). Remnant of lacinia relatively short (length about $70 \mu \mathrm{m}$ ), apically weakly sclerotized and slightly bidenticulate (Fig. 5b, c). Anterodorsal region of abdomen with a pair of small hemispherical humps (Fig. 6f). Terminalia (Figs 5f-g, 6c-e): Epiproct, paraproct and hypandrium simple, similar to those of S. zebrina (Lienhard, 2004: figs 14,15). Apex of dorsolateral appendages of 
phallosome rather abruptly narrowed (Figs $5 \mathrm{f}, 6 \mathrm{~d}$ ). Shape of apical part of phallosome variable due to movable distal structures and inflatable membranous blisters. For a view of all structures completely everted see Fig. $5 \mathrm{f}$, g; for apical structures retracted see Fig. 6c, d; for partially everted apical structures see Fig. 6e. Eversible structures lacking conspicuous hooked claspers but bearing a small finely spiculate conical lobe near opening of ejaculatory duct; this median lobe directed anteriad after eversion of the apical structures of the phallosome (Figs $5 \mathrm{f}, \mathrm{g}$ and $6 \mathrm{e}$ ); distal part of ejaculatory duct curved in retracted state (Fig. 6c, interrupted lines). Medioventral process (sensu Lienhard, 2004) posteriorly delimited by a transversal reticulate membrane bearing a pair of slightly sclerotized posterolateral lobes (Figs 5f, g and 6e); these conspicuous lobes also visible in retracted state (Fig. 6d). Measurements (HT except for wing lengths): $\mathrm{BL}=2.3 \mathrm{~mm} ; \mathrm{FW}=4.0 \mathrm{~mm}(\mathrm{PT}) ; \mathrm{HW}=2.7 \mathrm{~mm}(\mathrm{PT}) ; \mathrm{F}=846 \mu \mathrm{m} ; \mathrm{T}=1450$ $\mu \mathrm{m} ; \mathrm{t} 1=804 \mu \mathrm{m} ; \mathrm{t} 2=210 \mu \mathrm{m} ; \mathrm{t} 3=193 \mu \mathrm{m} ; \mathrm{IO} / \mathrm{D}=1.06$.

Etymology: The species is dedicated to my friend and colleague Thérèse Cuche (MHNG) in recognition of her invaluable assistance in my research on Psocoptera during more than 20 years. After retiring in 2007 she continues to work voluntarily for the Geneva Museum. Due to her competent sorting to morphospecies and labeling of the thousands of psocids collected by the TIGER-project this fascinating material became accessible to scientific studies.

Discussion: The new species is easy to distinguish from $S$. zebrina by the presence of a pair of small protuberances of the vertex, near the compound eyes (Fig. 5a), and of a pair of small hemispherical humps anterodorsally on the abdomen (Fig. 6f). These characters are probably present in both sexes, but as the female is unknown, the possibility of sexual dimorphism cannot be ruled out. Two colour characters should also be mentioned here, although probably of limited diagnostic value, i.e. the presence, in $S$. theresiae, of a brown transversal band in about $2 / 3$ of the femora (Fig. 5i) and of some brown pigmentation along the pterostigmal veins in the forewing (Fig. 6a). The phallosomes of the two species of Siamoglaris differ by the shape of the dorsolateral appendages, distally more abruptly narrowed in $S$. theresiae (Figs 5f, 6d) than in S. zebrina (Fig. 4), by the presence of a pair of sclerotized terminal claspers in S. zebrina (Fig. 4), absent in S. theresiae (Figs 5f, g and 6d, e), by the presence of a pair of slightly sclerotized lateral lobes at the posterior margin of the medioventral part in S. theresiae (Figs 5f, g and 6d, e), absent in S. zebrina (Fig. 4), and by some details of the eversible posterior structures, especially the presence, medially near the opening of the ejaculatory duct, of a spiculate conical lobe in S. theresiae (Figs 5g, 6e) which could not be observed in S. zebrina (Fig. 4b, c). The mechanism of everting the distal parts of the phallosome (observed in one paratype) corresponds to that described for S. zebrina. For S. theresiae it has to be noted that the characteristic spiculate conical lobe near the opening of the ejaculatory duct is difficult or impossible to observe in the retracted state (Fig. 6d).

Almost nothing is known about the biology of $S$. theresiae. The type locality is situated at the foot of a large limestone mountain with caves (e. g. Chiang Dao Cave) and subterranean crevices (Peter Schwendinger, pers. comm.). The paratypes were collected in a area with isolated limestone outcrops. Therefore it seems possible that 

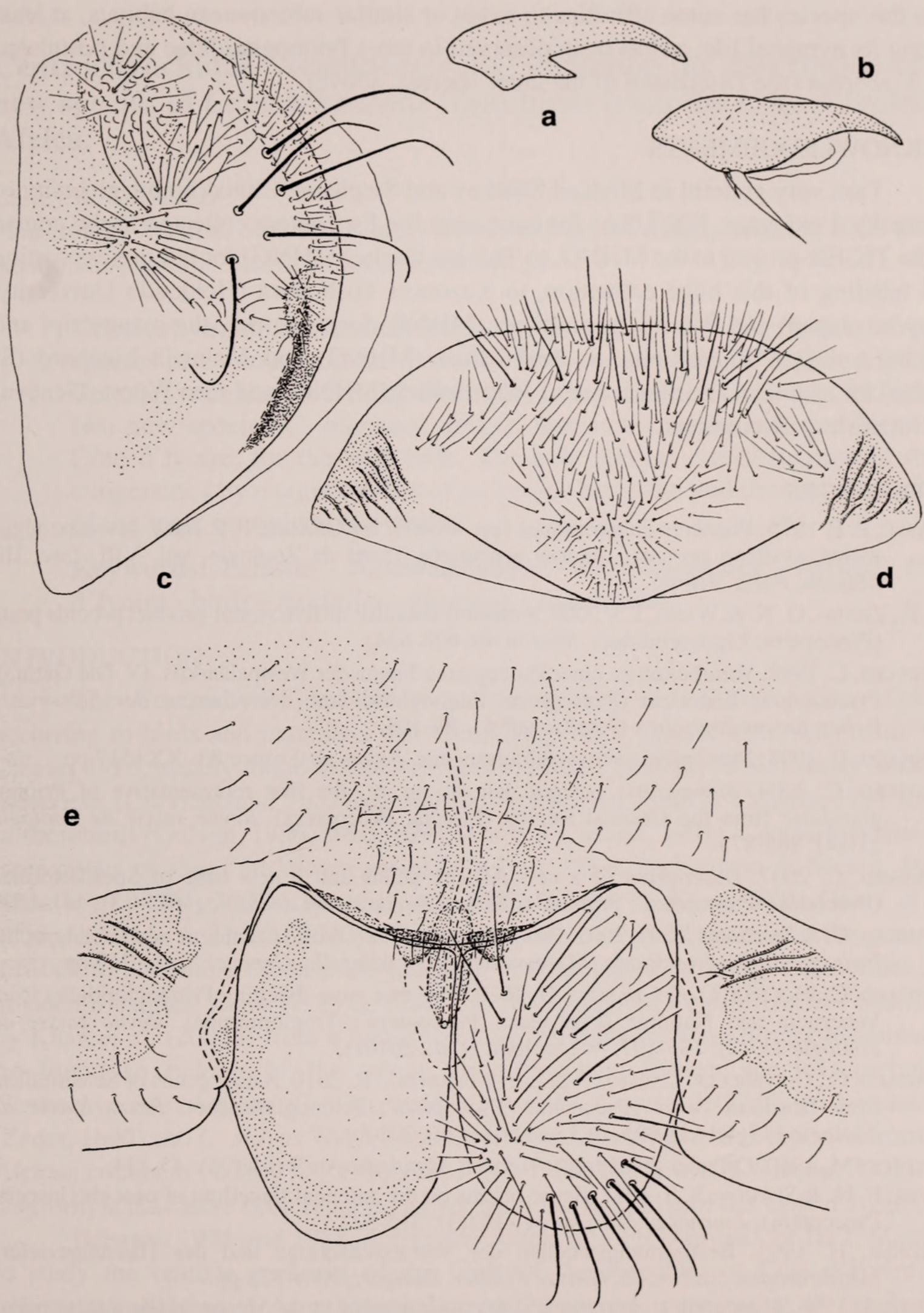

FIG. 7

Prionoglaris stygia Enderlein: (a) Posterior pretarsal claw of hindleg (internal view). (b) Anterior pretarsal claw of hindleg (external view). (c) Left paraproct of female (specimen from the type locality). (d) Epiproct of female (same specimen; posterior margin pointing to bottom of figure plate). (e) Subgenital plate, ovipositor valvulae (pilosity on right side not shown), ventrolateral parts of clunium, spermapore region and distal part of spermathecal duct (same specimen). 
also this species has some affinities to caves or similar subterranean habitats, at least during its nymphal life, as has been observed in most Prionoglarididae and postulated for $S$. zebrina (see Discussion of the latter species, above).

\section{ACKNOWLEDGEMENTS}

I am very grateful to Michael Sharkey and Stephanie Clutts (both University of Kentucky, Lexington, KY, USA) for entrusting the Psocoptera collected in the course of the TIGER-project to the MHNG, to Thérèse Cuche (MHNG) for her tireless sorting and labeling of this huge collection, to Kazunori Yoshizawa (Hokkaido University, Sapporo, Japan) and Peter Schwendinger (MHNG) for reviewing the manuscript and making valuable suggestions, to André Piuz (MHNG) and Manuela Lienhard (St Blaise) for technical assistance and to John Hollier (MHNG) and Jean Wüest (Geneva) for interesting discussions.

\section{REFERENCES}

GrassÉ, P. P. 1975. Phanères épidermiques (pp. 48-67). In: GrassÉ. P. P. (ed.). Insectes: téguments, système nerveux, organes sensoriels. Traité de Zoologie, vol. VIII, fasc. III. Masson, Paris, 910 pp.

Hu, F., ZHANG, G. N. \& WANG, J. J. 2009. Antennal sensillae of five stored-product psocids pests (Psocoptera: Liposcelididae). Micron 40: 628-634.

LIENHARD, C. 1988. Vorarbeiten zu einer Psocopteren Fauna der Westpaläarktis. IV. Die Gattung Prionoglaris Enderlein (Psocoptera: Prionoglarididae). Mitteilungen der Schweizerischen Entomologischen Gesellschaft 61: 89-108.

Lienhard, C. 1998. Psocoptères euro-méditerranéens. Faune de France 83: XX+517 pp.

LIENHARD, C. 2004. Siamoglaris zebrina gen. n., sp. n., the first representative of Prionoglarididae from the Oriental Region (Insecta: Psocoptera). Revue suisse de Zoologie 111(4): 865-875.

LiENHARD, C. 2007. Description of a new African genus and a new tribe of Speleketorinae (Psocodea: 'Psocoptera': Prionoglarididae). Revue suisse de Zoologie 114(3): 441-469.

Lienhard, C. \& Smithers, C. N. 2002. Psocoptera (Insecta): World Catalogue and Bibliography. Instrumenta Biodiversitatis (Muséum d'histoire naturelle, Genève) 5: xli+745 pp.

Lienhard, C., Holuša, O. \& Grafitti, G. 2010. Two new cave-dwelling Prionoglarididae from Venezuela and Namibia (Psocodea: 'Psocoptera': Trogiomorpha). Revue suisse de Zoologie 117(2): 185-197. (= Lienhard et al., 2010a).

Lienhard, C., Oliveira do Carmo, T. \& Lopes Ferreira, R. 2010. A new genus of Sensitibillini from Brazilian caves (Psocodea: 'Psocoptera': Prionoglarididae). Revue suisse de Zoologie 117(4): 611-635. (= Lienhard et al., 2010b).

Sellnick, M. 1960. Oribatei (Nachtrag). Tierwelt Mitteleuropas 3 (Lief. 4): 45-134.

SLIFER; E. H. \& SEKHON, S. S. 1977. Sense organs on the antennal flagellum of psocids (Insecta, Psocoptera). Journal of Morphology 151(3): 315-323.

WeIDNER, H. 1993. Bestimmungstabellen der Vorratsschädlinge und des Hausungeziefers Mitteleuropas. 5th rev. ed. Gustav Fischer, Stuttgart, XI + 328 pp.

WÜEST, J. 1996. L'appareil à phéromone d'Argynnis paphia et de Mesoacidalia aglaja mâles (Lépidoptères, Nymphalides) en microscopie électronique à balayage. Bulletin romand d'entomologie 14: 47-56.

Yoshizawa, K. \& Johnson, K. P. 2006. Morphology of male genitalia in lice and their relatives and phylogenetic implications. Systematic Entomology 31: 350-361.

Yoshizawa, K., Lienhard, C. \& Johnson, K. P. 2006. Molecular systematics of the suborder Trogiomorpha (Insecta: Psocodea: 'Psocoptera'). Zoological Journal of the Linnean Society 146: 287-299. 


\section{$2 \mathrm{BHL}$ Biodiversity Heritage Library}

Lienhard, Charles. 2011. "A new species of Siamoglaris from Thailand with complementary description of the type species (Psocodea: 'Psocoptera': Prionoglarididae)." Revue suisse de zoologie 118, 293-306.

https://doi.org/10.5962/bhl.part.117810.

View This Item Online: https://www.biodiversitylibrary.org/item/148548

DOI: https://doi.org/10.5962/bhl.part.117810

Permalink: https://www.biodiversitylibrary.org/partpdf/117810

\section{Holding Institution}

American Museum of Natural History Library

\section{Sponsored by}

BHL-SIL-FEDLINK

\section{Copyright \& Reuse}

Copyright Status: In copyright. Digitized with the permission of the rights holder.

Rights Holder: Muséum d'histoire naturelle - Ville de Genève

This document was created from content at the Biodiversity Heritage Library, the world's largest open access digital library for biodiversity literature and archives. Visit BHL at https://www.biodiversitylibrary.org. 